\title{
A Station-Based Southern Annular Mode Index from 1884 to 2005
}

\author{
MARTIN VISBECK \\ Leibniz-Institut für Meereswissenschaften, IFM-GEOMAR, Kiel, Germany
}

(Manuscript received 1 October 2007, in final form 6 June 2008)

\begin{abstract}
Atmospheric pressure observations from the Southern Hemisphere are used to estimate monthly and annually averaged indexes of the southern annular mode (SAM) back to 1884. This analysis groups all relevant observations in the following four regions: one for Antarctica and three in the subtropical zone. Continuous surface pressure observations are available at a number of locations in the subtropical regions since the end of the nineteenth century. However, year-round observations in the subpolar region near the Antarctic continent began only during the 1940-60 period. The shorter Antarctic records seriously compromise the length of a traditionally estimated SAM index. To improve the situation "proxy" estimates of Antarctic sea level pressure anomalies are provided based on the concept of atmospheric mass conservation poleward of $20^{\circ} \mathrm{S}$. This allows deriving a longer SAM index back to 1884 . Several aspects of the new record, its statistical properties, seasonal trends, and the regional pressure anomaly correlations, are presented.
\end{abstract}

\section{Introduction}

The southern annular mode (SAM) is a large-scale mode of atmospheric variability and arguably the most significant forcing of intraseasonal to decadal climate variability in the middle- to high-latitude Southern Hemisphere. Statistical analysis revealed a largely zonally symmetric atmospheric mass seesaw between the subtropical latitudes centered at $45^{\circ} \mathrm{S}$ and the Antarctic continent, which is characteristic of the strength and position of the circumpolar westerlies in models (e.g., Hall and Visbeck 2002; Visbeck and Hall 2004) and observations (e.g., Thompson and Wallace 2000). The same surface pressure anomaly pattern has also been referred to as the "high-latitude mode," "Antarctic Oscillation," or "Southern Hemispheric annual mode" (e.g., Kidson 1999; Thompson and Wallace 2000). Several studies have examined the expected impacts of changes in the SAM with regards to the atmosphere (e.g., Silvestri and Vera 2003; Gillett et al. 2006; Hendon et al. 2007), ocean circulation (e.g., Hall and Visbeck 2002; Oke and England 2004; Sen Gupta and England 2006; Fyfe and Saenko 2006; Meredith et al. 2004;

\footnotetext{
Corresponding author address: Martin Visbeck, Leibniz-Institut für Meereswissenschaften, IFM-GEOMAR, Düsternbrooker Weg 20, D-24105 Kiel, Germany.

E-mail: mvisbeck@ifm-geomar.de
}

Meredith and Hogg 2006; Verdy et al. 2006), and sea ice (Lefebvre et al. 2004; Gordon et al., 2007). More recently, the connections with marine $\mathrm{CO}_{2}$ uptake have been discussed in the context of both changes in ocean ventilation and $\mathrm{CO}_{2}$ solubility as well as biological productivity (e.g., Lovenduski and Gruber 2005; Lovenduski et al. 2007; Lenton and Matear 2007; Butler et al. 2007).

In the recent three decades the SAM has exhibited an upward trend since 1970. Its interaction within the Southern Hemisphere climate system has received significant attention (Thompson et al. 2000; Thompson and Solomon 2002; Gillett and Thompson 2003; Marshall 2003). Some authors have attributed the trend to anthropogenic changes in the middle atmosphere resulting from ozone depletion (e.g., Kushner et al. 2001; Thompson and Solomon 2002; Arblaster and Meehl 2006), and several papers discuss the future of the SAM given future $\mathrm{CO}_{2}$ emission and ozone concentration scenarios (e.g., Fyfe et al. 1999; Sexton 2001; Cai et al. 2003; Miller et al. 2006; Cai and Cowan 2007).

All of the studies make use of a SAM index to describe or explain observed climate impacts or hypotheses of climate feedbacks. Most of these lines of research would benefit from longer SAM time series, for example, to evaluate the significance of decadal trends or to calibrate proxy records based on either ice cores (Goodwin et al. 2004; Schneider et al. 2006) or tree rings 
(Jones and Widmann 2003). Gong and Wang (1999) proposed an ad hoc definition of the SAM index using the difference between the zonally averaged pressure fluctuations computed from gridded sea level reanalysis between $40^{\circ}$ and $65^{\circ} \mathrm{S}$. Other studies favored an EOFbased analysis of either the 500- or 850-hPa geopotential height anomaly (Mo 2000; Thompson and Wallace 2000). Marshall (2003) discussed potential trend and bias issues for the SAM index calculation based on gridded fields from atmospheric reanalyses of the presatellite era. Particularly problematic are SAM index estimates based on the early part of the National Centers for Environmental Prediction-National Center for Atmospheric Research (NCEP-NCAR) atmospheric reanalysis in the presatellite era (Hines et al. 2000). There is one fully interpolated and gridded sea level pressure (SLP) dataset based on ship and land station observations, the Hadley Centre mean SLP dataset, version 2 (HadSLP2; discussed by Allan and Ansell 2006). However, the uncertainties in the region south of $30^{\circ} \mathrm{S}$, which is of interest here, are quite large, and the marine coverage is very seasonally biased.

Given the issues with gridded fields, Marshall (2003) generated a station-based SAM index. His index is based on 12 selected stations, equally distributed between the subtropical and subpolar regimes. However, the absence of systematic pressure observations from the Antarctic continent limits the index to the post-1958 era. Jones and Widmann (2003) proposed a method to extend their SAM index back in time based on a statistical regression technique. The station weights were obtained by a detrended EOF analysis deduced from the gridded NCEP-NCAR reanalysis data.

Here a different method is used to extend the SAM index back to 1884 . In the following a brief description of the datasets and methods used is given. Then, its statistical properties, monthly trends, regional coherence, and selected impacts are discussed.

\section{Data and methods}

A Southern Hemisphere pressure dataset based on the Global Historical Climatology Network (GHCN) with data from about 1840 to 2005 was provided (Jones 1991). For each station the average seasonal cycle was removed and all data points outside four standard deviations were flagged as suspicious.

\section{a. Regionally based SAM index}

In recognition of the zonal symmetry of the SAM (e.g., Gong and Wang 1999), a bootstrap method was applied to derive an observationally based SAM index based on a combination of many subtropical and sub- polar sea level pressure time series. In the subpolar region the station spacing along the Antarctic coast is relatively homogeneous and a simple average seemed appropriate. In the subtropical regime the stations are largely concentrated in areas near the three continents with few island stations in-between. A practical way forward was to divide the subtropical belt into three sectors, thereby ensuring a somewhat equal contribution from each sector regardless of the number of stations in each sector. Such a clustering of the stations is supported by statistical analyses of the station data, for example, by EOF analysis of the stations (not shown). The spatial decorrelation scale was estimated from one-point correlation maps computed from the NCEPNCAR reanalysis data along $40^{\circ} \mathrm{S}$ and was found to be $\sim 60^{\circ}$ longitude. Both analysis and the high correlation with the regional index (Table 1) support the chosen clustering of the stations into three subtropical regions.

Following these considerations the SAM index was calculated using a two-step procedure. In a first pass only stations with more than $75 \%$ of valid monthly data between 1970 and 2000 and with a height below the 950-hPa pressure surface were retained. The remaining stations (Table 1) were then grouped into four regions: a polar region between $90^{\circ}$ and $65^{\circ} \mathrm{S}$ [Antarctica (AN)], and three subtropical ring segments between $58^{\circ}$ and $25^{\circ} \mathrm{S}$ from $10^{\circ} \mathrm{W}$ to $80^{\circ} \mathrm{E}$ [South Africa (AF)], from $80^{\circ} \mathrm{E}$ to $120^{\circ} \mathrm{W}$ [Australia-New Zealand (AU)], and from $120^{\circ}$ to $10^{\circ} \mathrm{W}$ [South America (SA)]. For each region an averaged pressure anomaly time series was constructed giving equal weights to each station. Next, four indexes were generated normalizing the regional mean time series by its standard deviation. The three subtropical indexes were then averaged to arrive at an average subtropical index $[\mathrm{ST}=(\mathrm{SA}+\mathrm{AF}+\mathrm{AU}) / 3]$. Together with the index from Antarctica a preliminary SAM index was obtained by the difference between the subtropical and subpolar index $(\mathrm{SAM}=\mathrm{ST}-\mathrm{AN})$.

In a second step for each station a correlation with the preliminary SAM index was calculated. Only stations with $\mathrm{SAM}_{\text {prelim }}$ index correlations above 0.25 for the subtropical regions and better than -0.4 for the Antarctic zone were retained for the final estimate. Based on the reduced set of stations for each sector final regional pressure anomaly indexes were constructed (Fig. 1a). Some stations in the South American and Australian sector began already in 1858 , but only since 1884 did a reasonable number of stations report, ensuring a minimum spatial coverage outside Antarctica. A few Antarctic stations became available after 1945, but good coverage was only reached post-1958. From the remaining 20 stations for Antarctica, 6 for South Africa, 10 for Australia-New Zealand, and 7 for South 
TABLE 1. Stations used for the SAM index calculation grouped in four regions. The position, start year, correlation with the monthly SAM index, and the correlation with the regional averaged pressure anomaly are given.

\begin{tabular}{|c|c|c|c|c|c|}
\hline Station name & Lat $\left(^{\circ}\right)$ & Lon $\left(^{\circ}\right)$ & Start of record & SAM correlation & Regional correlation \\
\hline \multicolumn{6}{|l|}{ Antarctica } \\
\hline Esperanza + Hope Bay & -63.4 & 303.0 & 1945 & -0.73 & 0.86 \\
\hline Orcadas & -60.8 & 315.3 & 1903 & -0.40 & 0.73 \\
\hline Halley Bay & -75.5 & 333.4 & 1956 & -0.82 & 0.82 \\
\hline Signy Island & -60.7 & 314.4 & 1947 & -0.62 & 0.75 \\
\hline Bellinghausen & -62.2 & 301.1 & 1944 & -0.66 & 0.82 \\
\hline Marambio & -64.2 & 303.3 & 1971 & -0.72 & 0.83 \\
\hline Frei & -62.2 & 301.0 & 1969 & -0.60 & 0.77 \\
\hline B. A. Arturo Prat & -62.5 & 300.3 & 1966 & -0.62 & 0.78 \\
\hline Bernado O'Higgins & -63.3 & 302.1 & 1963 & -0.65 & 0.78 \\
\hline Rothera, $68^{\circ} \mathrm{S}$ & -67.6 & 291.9 & 1946 & -0.69 & 0.82 \\
\hline Faraday and Port Lockroy & -65.2 & 295.7 & 1944 & -0.67 & 0.82 \\
\hline Novolazarev & -70.8 & 11.8 & 1961 & -0.77 & 0.72 \\
\hline Syowa & -69.0 & 39.6 & 1957 & -0.79 & 0.78 \\
\hline Molodznaja & -67.7 & 45.9 & 1963 & -0.81 & 0.81 \\
\hline Mawson & -67.6 & 62.9 & 1954 & -0.75 & 0.75 \\
\hline Davis & -68.6 & 78.0 & 1957 & -0.78 & 0.77 \\
\hline Mirny & -66.5 & 93.0 & 1956 & -0.72 & 0.71 \\
\hline Casey & -66.3 & 110.5 & 1957 & -0.74 & 0.73 \\
\hline Dumont Durville & -66.7 & 140.0 & 1956 & -0.69 & 0.66 \\
\hline Scott & -77.8 & 166.8 & 1957 & -0.73 & 0.67 \\
\hline \multicolumn{6}{|l|}{ South Africa } \\
\hline Durban & -30.0 & 30.9 & 1884 & 0.50 & 0.89 \\
\hline Port Elizabeth & -34.0 & 25.6 & 1887 & 0.53 & 0.92 \\
\hline Cape Town & -34.0 & 18.6 & 1841 & 0.44 & 0.76 \\
\hline Maputo & -25.9 & 32.6 & 1910 & 0.44 & 0.86 \\
\hline Gough Island & -40.4 & -9.9 & 1942 & 0.33 & 0.39 \\
\hline Marion Island & -46.9 & 37.9 & 1948 & 0.33 & 0.45 \\
\hline \multicolumn{6}{|l|}{ Australia and New Zealand } \\
\hline Christchurch & -43.5 & 172.6 & 1864 & 0.40 & 0.90 \\
\hline Adelaide & -34.9 & 138.5 & 1857 & 0.24 & 0.55 \\
\hline Auckland & -37.0 & 174.8 & 1863 & 0.37 & 0.83 \\
\hline Dunedin Airport & -45.9 & 170.2 & 1864 & 0.39 & 0.88 \\
\hline Wellington & -41.3 & 174.8 & 1864 & 0.41 & 0.92 \\
\hline Sydney & -34.0 & 151.2 & 1859 & 0.30 & 0.68 \\
\hline Hobart Airport & -42.8 & 147.5 & 1866 & 0.30 & 0.75 \\
\hline Hokitika & -42.7 & 171.0 & 1866 & 0.42 & 0.93 \\
\hline Chatham Island & -44.0 & 183.4 & 1930 & 0.38 & 0.82 \\
\hline Campbell Island & -52.5 & 169.2 & 1941 & 0.21 & 0.62 \\
\hline \multicolumn{6}{|l|}{ South America } \\
\hline Asuncion & -25.3 & 302.4 & 1893 & 0.41 & 0.78 \\
\hline Cordoba Argenti & -31.4 & 295.8 & 1873 & 0.49 & 0.93 \\
\hline Bahia Blanca AE & -38.7 & 297.8 & 1860 & 0.48 & 0.91 \\
\hline Montevideo & -34.9 & 303.8 & 1883 & 0.47 & 0.89 \\
\hline Buenos Aires & -34.6 & 301.5 & 1858 & 0.51 & 0.94 \\
\hline Neuguen & -39.0 & 291.9 & 1916 & 0.45 & 0.90 \\
\hline Trelew & -43.2 & 294.7 & 1916 & 0.41 & 0.85 \\
\hline
\end{tabular}

America (Fig. 2; Table 1), a final station-based SAM index was derived covering the time span from 1945 to 2005 (Fig. 1b).

This SAM index compares well to that of Marshall (2003) from the British Antarctic Survey (BAS); he has analyzed the same dataset using a different method of selecting and processing subtropical stations. The correlation between his BAS-SAM index and the new one is 0.85 , significant at the $95 \%$ level (Table 2). Both methods depend crucially on Antarctic stations and thus the indexes are limited to the post-1945 era.

\section{b. Reconstructing Antarctic pressure anomalies prior to 1945}

The earliest pressure time series in the Antarctic sector come from the Orcadas station at $60^{\circ} \mathrm{S}$ on the 

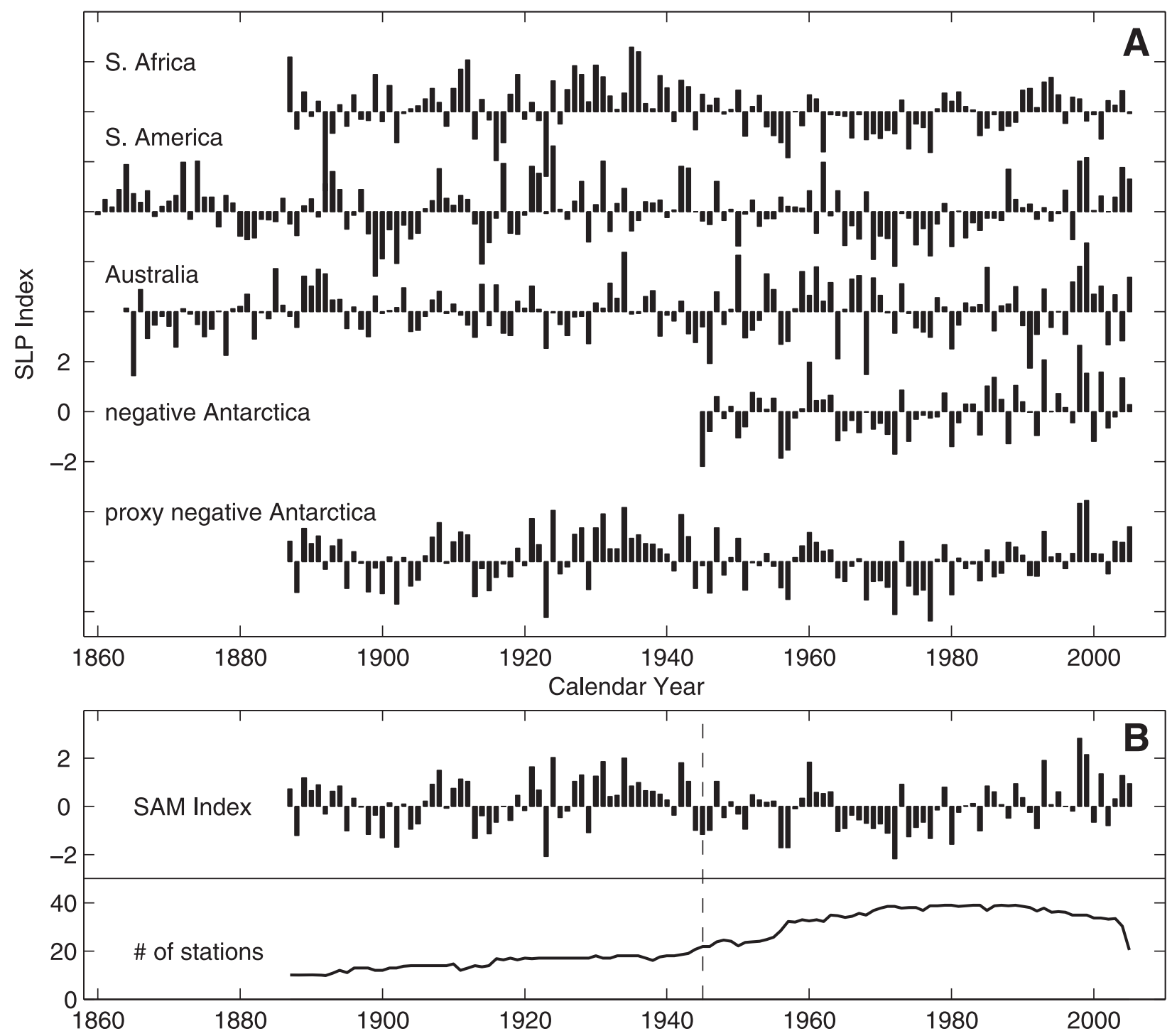

FIG. 1. (a) The top four time series represent annual averaged SLP indices for the regions of South Africa, South America, AustraliaNew Zealand, and Antarctica (see also Table 1 for the names of individual stations). Note that the pressure anomalies for Antarctica have been reversed to better show the expected anticorrelation with the SAM. The bottom time series depicts the reconstructed index for Antarctica based on the upper three time series. (b) The final annually averaged SAM index is shown together with the number of individual stations that have been used. The dashed line indicates the year 1945. Before 1945 the proxy SLP index for Antarctica was used to derive the SAM index.

Antarctic Peninsula that has reported since 1903. However, its location near the node of the SAM pressure seesaw and associated low correlation with the SAM makes it only marginally useful as a proxy for pressure fluctuations in the subpolar regime. Between 1944 and 1946 three more stations began continuous observations: Bellinghausen, Esperanza, and Rothera, all of which are south of $63^{\circ} \mathrm{S}$. These can be used to provide an early record of Antarctic pressure anomalies. Since 1957 more than 10 stations with significant SAM correlation are available (Table 1) allowing for a stable estimate of subpolar pressure fluctuations around Antarctica.

To extend the length of the SAM index a method was developed to obtain a "proxy" estimate for the subpolar (Antarctic) pressure fluctuation. This method is based on the assumption that to first order a meridional atmospheric mass seesaw is responsible for the observed SAM related surface pressure fluctuations. Mass conservation suggests that a lower-than-normal pressure for the Antarctic region must be balanced by a higherthan-normal pressure equatorward. The new "proxy" 


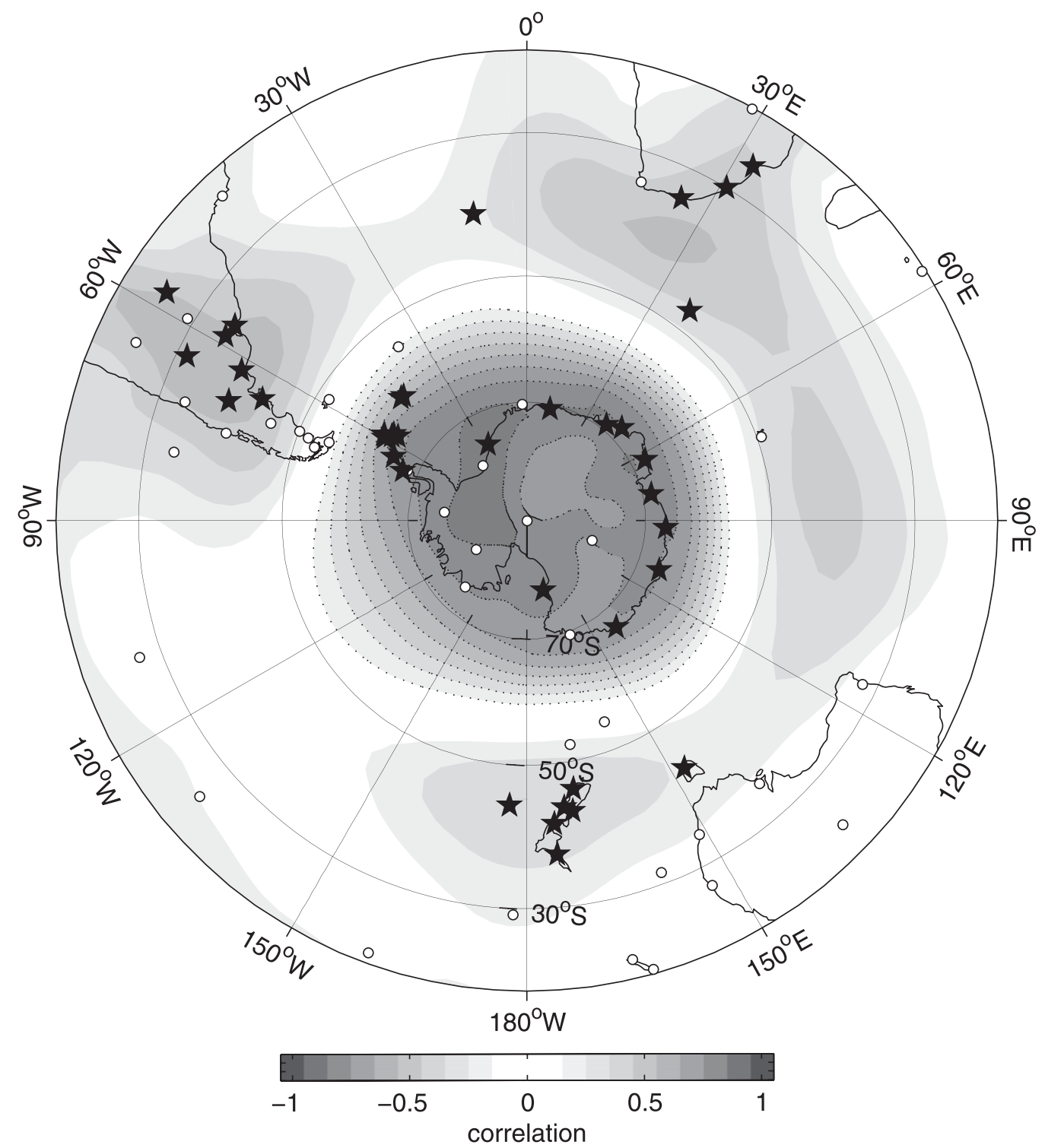

FIG. 2. Black stars represent locations of SLP stations used for SAM index calculation. Open circles represent other stations not used here. Gray shading represents the correlation between the monthly SAM index and the NCAR-NCEP reanalysis 850-hPa geopotential anomaly between 1970 and 2002. Negative correlation is indicated by dotted contour lines.

estimate tries not to precisely close the atmospheric mass balance because not enough equally spaced pressure observations are available. To keep matters simple the variance-normalized pressure indexes for the three subtropical regions are used with equal weights. This is reasonably justified because the level of pressure variance is quite similar across the three subtropical regions. What is not well known is the spatial representativeness of the regions, so it is assumed to be equal.

Figure 3 a shows the covariance of the monthly station pressure data with the SAM index as a function of lat- itude. The pressure changes in the subpolar region are about twice as large when compared to the subtropical stations. However, when each pressure anomaly is multiplied by the length of the corresponding latitude circle a more consistent picture emerges (Fig. 3b). After this normalization the atmospheric mass seesaw with a zero line at about $58^{\circ} \mathrm{S}$ visually becomes evident. Fitting a curve to all stations (Fig. 3b, thin line) allows for quantification of the mass imbalance. The difference of the pressure anomalies north and south of $58^{\circ} \mathrm{S}$ is less than $10 \%$ of each sum. With the expected scatter of 
TABLE 2. Correlation between four regions, proxy Antarctica, and the new SAM index post-1958 and pre-1940. A SAM index just based on 16 subtropical stations that have data since 1910 is also presented. For reference the correlations between other SAM indexes from Marshall (2003; BAS SAM) and Jones and Widmann (2003; GKSS SAM) are shown. Values that are not significant at the $95 \%$ level are printed in italic font.

\begin{tabular}{|c|c|c|c|c|c|c|}
\hline Region & SAM & SA & $\mathrm{AF}$ & $\mathrm{AU}$ & AN & AN_proxy \\
\hline Monthly index & This index & South America & South Africa & $\begin{array}{c}\text { Australia, } \\
\text { New Zeeland }\end{array}$ & Antarctica & $\begin{array}{c}\text { Reconstructed } \\
\text { Antarctica }\end{array}$ \\
\hline $\begin{array}{r}\text { 1958-2005 this SAM } \\
\text { Annual index }\end{array}$ & 1.0 & 0.49 & 0.57 & 0.42 & -0.92 & -0.80 \\
\hline 1958-2005 this SAM & 1.0 & 0.67 & 0.39 & 0.53 & -0.94 & -0.86 \\
\hline 1884-1940 this SAM & 1.0 & 0.68 & 0.62 & 0.51 & No data & -1.0 \\
\hline 1958-2005 16-station SAM & 0.72 & 0.23 & 0.43 & 0.38 & -0.73 & -1.0 \\
\hline 1958-2004 BAS SAM & 0.85 & 0.39 & 0.39 & 0.63 & -0.79 & -0.75 \\
\hline 1910-2001 GKSS SAM & 0.54 & 0.39 & 0.04 & 0.61 & Incomplete & -0.55 \\
\hline
\end{tabular}

individual stations in mind this provides reasonable justification to consider the SAM to first order as a meridionally mass-balanced seesaw in a zonally averaged sense. Thus, the pressure anomalies in the band between $58^{\circ}$ and $25^{\circ} \mathrm{S}$ could indeed serve as a (inverse) proxy for the pressure anomaly south of $58^{\circ} \mathrm{S}$.

Based on this assumption an Antarctic "proxy" pressure index was constructed using the averaged subtropical index: $\mathrm{AN}_{\text {proxy }}=-\mathrm{ST}$. Comparison of the proxy and observed time series for the Antarctic region post-1958, where both estimates exist, provides a further consistency check (Fig. 1, Table 2). The correlation between the observed $\mathrm{AN}$ index and $\mathrm{AN}_{\text {proxy }}$ is 0.64 for annually averaged data and is significant at the $95 \%$ level. Possibly more relevant is the correlation between $\mathrm{AN}$ index and SAM and $\mathrm{AN}_{\text {proxy }}$ index and the SAM index. Table 2 shows that for both monthly and annually averaged data the correlations drop only from 0.9 for the databased index to 0.8 for the proxy index, but they remain high and significant. The regional correlation between the SAM and the subtropical regional indexes before (1884-1940) and after (1958-2005) the Antarctic stations became available is only slightly larger, with the exception of South Africa, where a significantly higher correlation for the early period is found.

The new "proxy" Antarctic pressure index allows for extension of a combined SAM index back to 1884 (Fig. $1 b)$. The full SAM index is based on more than 13 stations after 1884, increasing to more than 20 subtropical stations by 1940 (Table 1). To estimate whether the changing number of stations has a significant impact on the SAM index an alternative $\mathrm{AN}_{\text {proxy_16 }}$ index was computed from 16 subtropical stations that all had data since 1910. The correlation of this index is lower when compared to the full dataset, but still at a reasonable level (Table 2). Overall, the correlation analysis suggests that this approach has merit and can extent the SAM index back to 1884 .

\section{SAM index properties}

The SAM exhibits significant monthly variability. The spatial correlation between the monthly SAM index and $850-\mathrm{hPa}$ geopotential height from the NCEP-NCAR reanalyzed anomalies is shown in Fig. 2. Not surprisingly the shape resembles many other depictions of the SAM (e.g., Gong and Wang 1999), with the lowest correlations in the subtropical eastern Pacific sector. The covariance of the station-based pressure anomalies with the monthly SAM index is shown in Fig. 3a as a function of latitude. South of $58^{\circ} \mathrm{S}$ the pressure is typically lowered by $3-4 \mathrm{hPa}$ during a +1 SAM index phase. The corresponding pressure increase between $58^{\circ}$ and $25^{\circ} \mathrm{S}$ is because of the larger area being smaller and about $1-2 \mathrm{hPa}$. Equatorward of $20^{\circ} \mathrm{S}$ only very small and partially insignificant SAM-related pressure anomalies are found.

Figure 4 shows for each calendar year the number of month exceeding an absolute SAM index value of 1.2. Only few years exist where all months are either insignificant or of one SAM index sign. Notable exceptions are the 1968-72 period and recent years.

The annual SAM index is defined here as the averaged monthly index anomaly using all months of each calendar year. This index exhibits interannual autocorrelations close to 0.2 out to a 6 -yr lag (Fig. 5). Based on a bootstrap Monte Carlo significance test the values are just below the boundary of statistical significance at the $95 \%$ level. For lags longer than $1 \mathrm{yr}$ the autocorrelations for the annual SAM index are larger when compared to those of the winter North Atlantic Oscillation (NAO) index. This could be seen as a hint supporting the notion of some amount of long-term "memory" (e.g., Fyfe and Saenko 2006). However, a convincing case can only be made if a plausible mechanism is advanced. The statistical properties are consistent with a white noise hypothesis. 

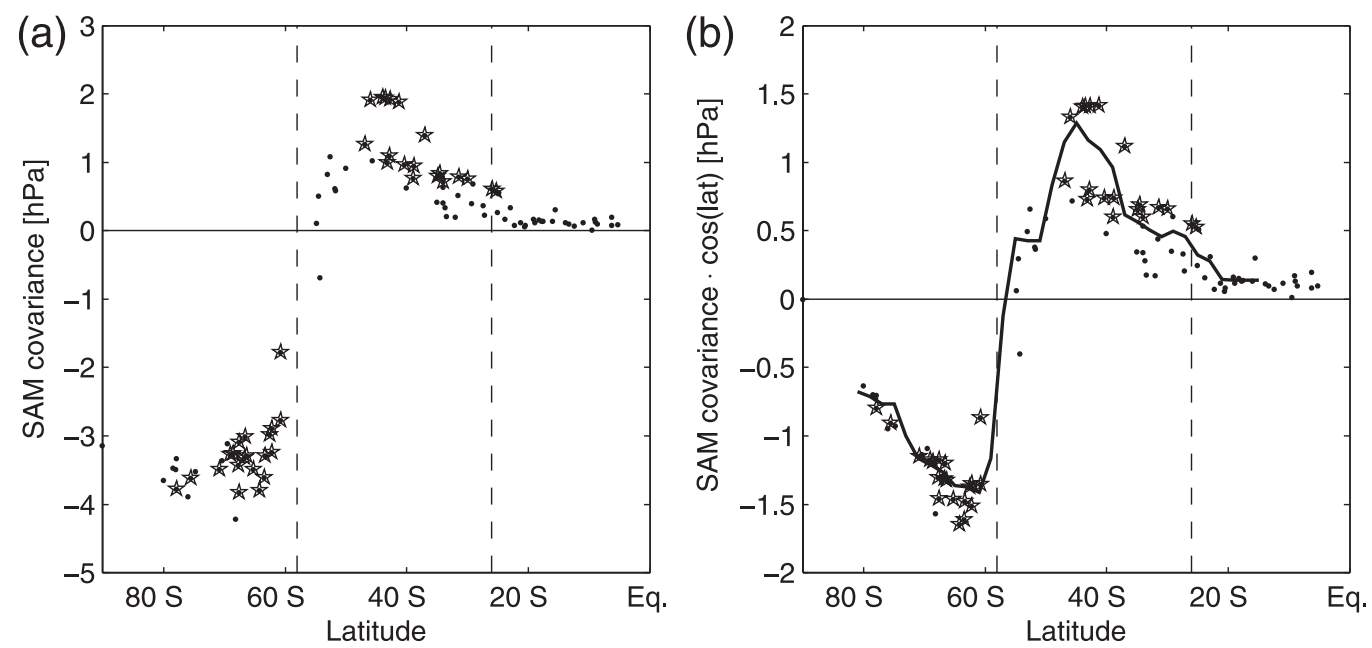

FIG. 3. (a) Covariance between the monthly SAM index and the station-based pressure anomaly as a function of station lat. Stars denote stations used for the SAM index calculations and the dots are other available station data. (b) Similar to (a), but here the values are normalized by the area (multiplied by the cosine of the latitude). The thin solid line is estimated using the median value from all station data within a $3^{\circ}$ latitude band.

Figure 6 and Table 2 show the correlations between the annual SAM and the four regional pressure indexes for the time span of good data coverage between 1958 and 2005. As expected, the highest correlation is found for the Antarctic region, with -0.95 . The subtropical pressure anomalies show a lower correlation between 0.3 and 0.7 , with the SAM index, but they are still significant at the $95 \%$ level. Interestingly, the correlation between neighboring subtropical stations is not significantly different from zero. The low correlations imply that for each year the mass seesaw between the subpolar and subtropical regions is not ring-like, but rather dominated by a specific sector. Inspections of one-point correlation maps based on the NCEP-NCAR reanalysis along longitudes in the $40^{\circ}-30^{\circ} \mathrm{S}$ band confirm a spatial decorrelation pattern of wavenumber 3-4, consistent with the low correlations shown here. It is possible to construct more regional SAM indexes based on the pressure difference for each one of the three subtropical regions and Antarctica. Their correlation with the full SAM is quite large, typically exceeding 0.8 , because of the important contribution from the Antarctic stations.

The new, much longer SAM index allows for reevaluation of decadal trends in the record. Between 1970 and 2000 a trend from a negative to a positive SAM index is found in agreement with other SAM index estimates (e.g., Thompson and Solomon 2002). How unusual is the recent trend in comparison to earlier times

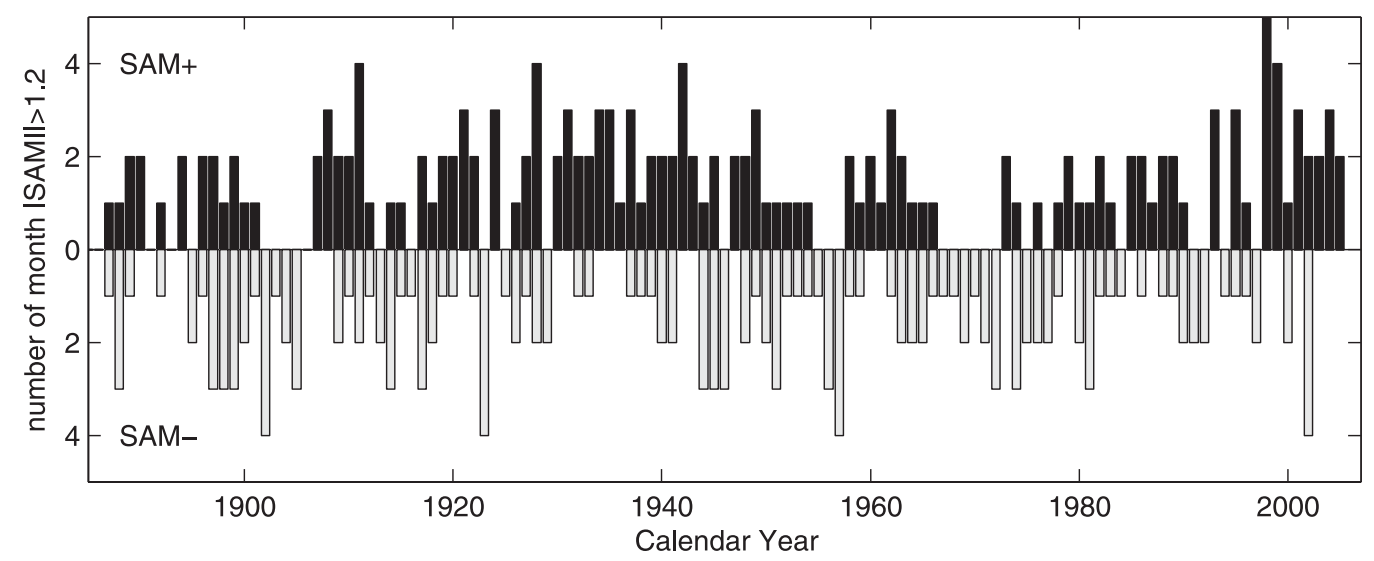

FIG. 4. Number of monthly SAM index values for each calendar year that are greater than 1.2. The solid upper black bars represent months with a positive index value. The open lower bars represent the number of months with SAM index values less than -1.2 . 


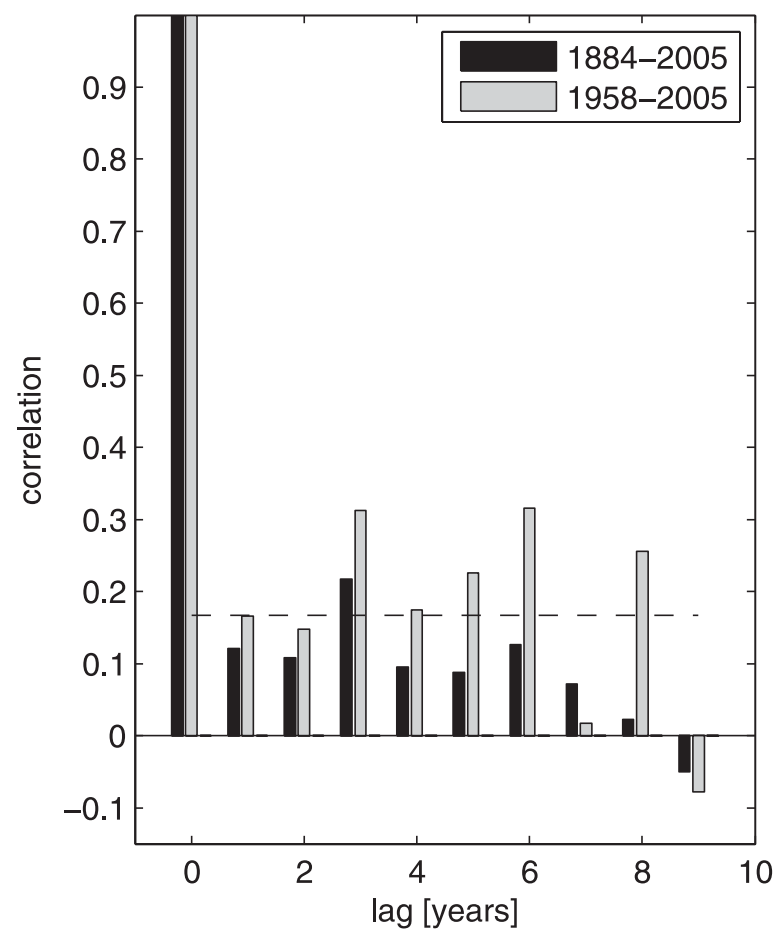

FIG. 5. SAM index lag autocorrelation for annual data based on two periods. The solid bars represent the full time series, while the gray bars are restricted to the period where pressure observations exist for Antarctica (1958-2005). The dashed lines are autocorrelations that could be found resulting from sampling errors for a 120 -yr-long time series of white noise.

in the SAM record? Figure 7 displays the 20- and 30-yr linear trend estimates every $5 \mathrm{yr}$ based on the annual SAM index. The maximum value of the recent $30-y r-$ long SAM trend centered on 1985 was indeed the strongest upward trend throughout the record. However, a similarly strong decrease in the SAM index occurred before centered on 1945. Reducing the baseline length for the linear trend estimate to $20 \mathrm{yr}$ reveals that the last three trend estimates centered on 1980, 1985, and 1990 all show similar strongly positive values. Only once before, between 1915 and 1935, was a similarly strong upward trend recorded.

Is the recent trend between 1970 and 2005 similar and remarkable for all months of the year? When estimating the change of the SAM index resulting from the 35-yr linear trend for each month separately and comparing it to the interannual long-term variability 6 months stand out: December-January, April-May, and July-August; they all show an index trend of more than 1.5 over the 35-yr period (Fig. 8). The recent SAM index change for the other months, however, is still within the long-term variability. Both analyses show that the over 100 -yr-long SAM index gives a more cautionary perspective when it comes to the attribution of recent SAM trend signals.

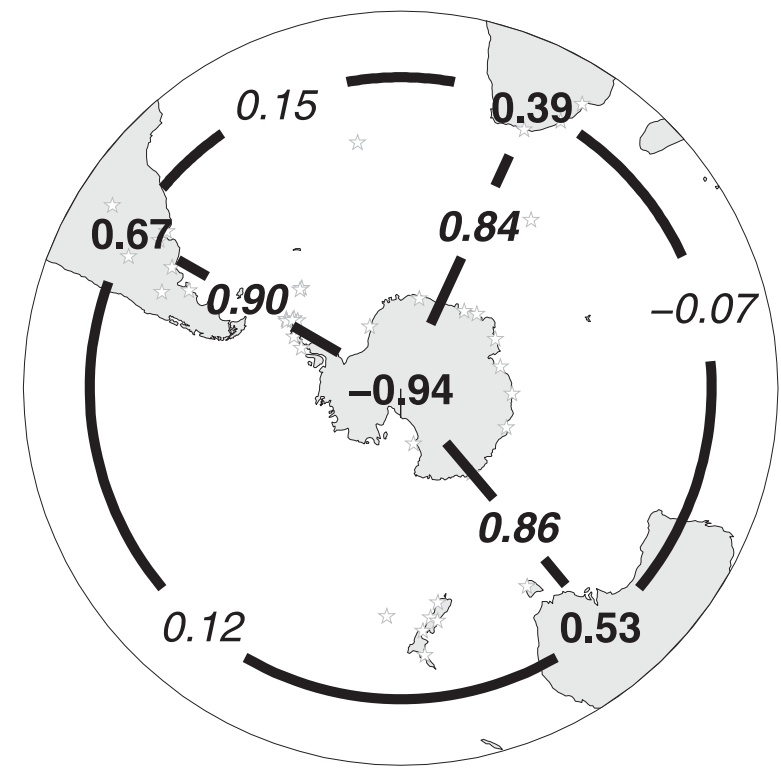

FIG. 6. Annual correlation between the four annually averaged regional pressure indexes and the SAM index between 1958 and 2005 is shown in bold font. The correlation between the three neighboring subtropical regions is shown with light italic font in the outer circle. The correlation between each of the three regional SAM indexes defined as the difference between one subtropical region and Antarctica is represented by italic bold font. Stars indicate the stations used for the estimation of the pressure indexes.

\section{Summary and discussion}

A technique has been developed to estimate the amplitude of the Southern Annular Mode from sea level pressure station observations since 1884 . The same data have been analyzed with regards to the SAM before by Marshall (2003) and Jones and Widmann (2003). However, the methods applied to construct a SAM index differ between the studies. Here the station data are grouped into four regions of the Southern Hemisphere to ensure a reasonable amount of spatial coverage. The correlation of the new SAM index with that of Marshall (2003; BAS-SAM) and of Jones and Widmann (2003; GKSS Research Center, Geesthacht, Germany, SAM) are given in Table 2. The new SAM index compares well to the BAS-SAM index with a correlation of 0.85 for the annual index for the joint period between 1958 and 2005.

Based on the assumption that mass is conserved poleward of $20^{\circ} \mathrm{S}$, it was possible to estimate pressure anomalies over Antarctica based solely on the observations from the subtropical belt. Several consistency checks were presented to show that this approach is indeed a reasonable way forward to estimate the pre1950 state of the southern annular mode. 

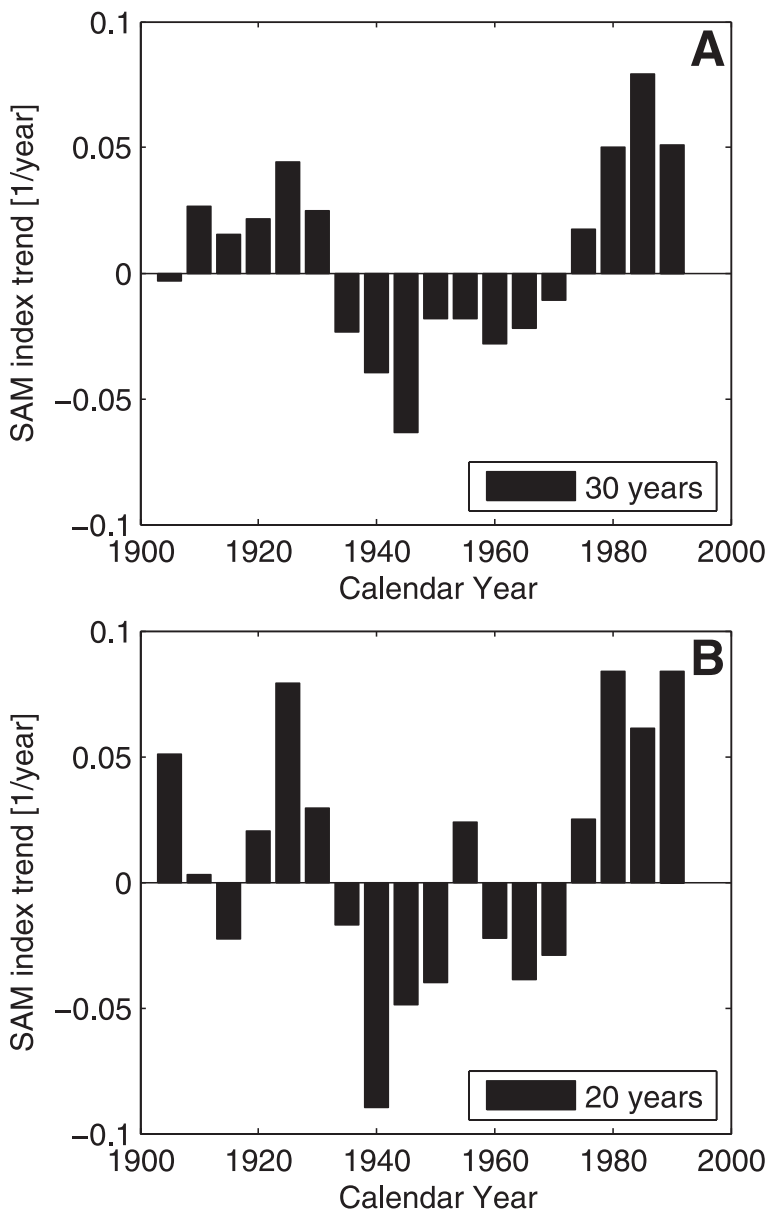

FIG. 7. Linear trends for the annual SAM index computed every $5 \mathrm{yr}$. (a) Trends estimated over a base period of $30 \mathrm{yr}$ and (b) trends estimated over a base period of $20 \mathrm{yr}$.

An additional test was made to check what influence an increasing number of stations might have on the regional time series. For example, a proxy Antarctic pressure index was calculated from a reduced set of 16 subtropical stations, which all have data since 1910. The correlation between the full series with an increasing number of stations and the reduced set is 0.96 for the annual mean SAM index values. Thus it seems that regional averaging ensures that increases in the observing system have no measurable effect on the longer SAM index reconstruction.

The Jones and Widmann (2003) GKSS SAM index compares less well to the new SAM. The correlation of annual values between 1910 and 2001 is only 0.54 . Jones and Widmann make significant use of the Ushuaia station, which in their particular EOF pattern has a negative correlation with the SAM (their Fig. 1). In our analysis the station was not used because of a low correlation with the preliminary SAM index. All of the

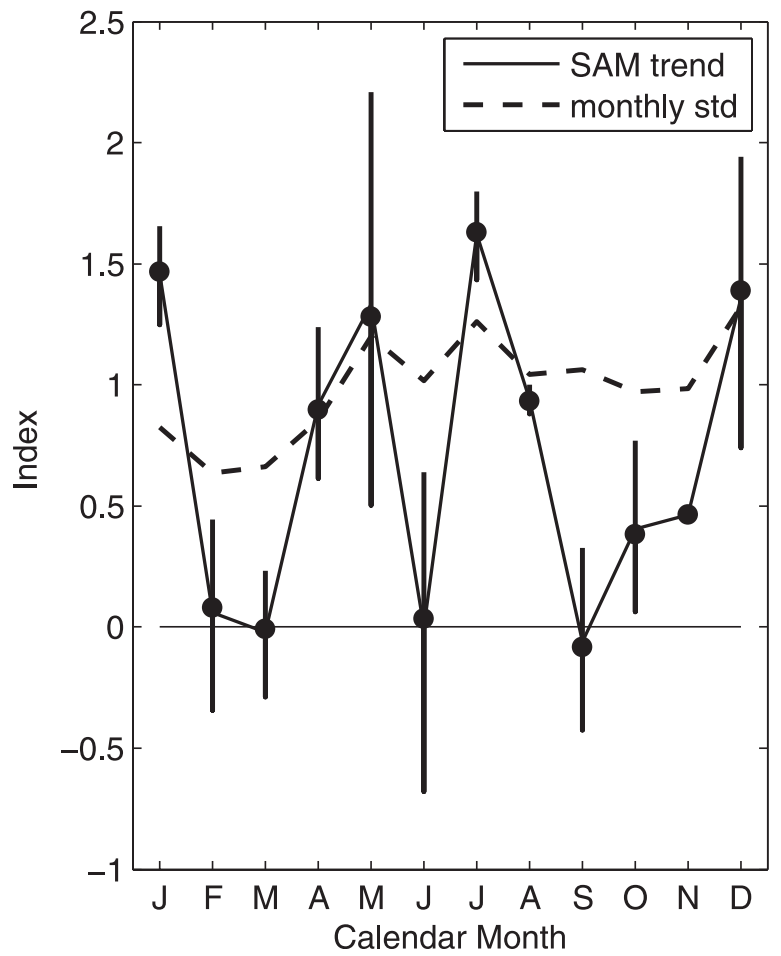

FIG. 8. SAM index change resulting from linear trend between 1970 and 2005 as a function of month of the year is given by the solid dots. The vertical lines represent the uncertainty of the trends. The dashed line denotes the interannual index std dev for each calendar month.

other stations from their analysis are from what here is called the Australian sector. Thus, their index is more similar to our Australia SLP index than the full SAM index, which is also evident from the relatively high correlation with our AU index (Table 2).

To achieve some degree of equal spatial representation the three subtropical regions were chosen near the continents. Interestingly, the pressure anomalies of the three subtropical regions are practically uncorrelated. Thus, the simple concept of a ring-like mass seesaw does not seem appropriate; rather, individual months or years are characterized with a redistribution of mass between Antarctica and a particular region in the subtropical belt. This is also consistent with the generally lower correlation values of geopotential height anomalies found in the classical SAM EOF analyses (e.g., Thompson and Wallace 2000).

For oceanographic applications, however, one of the most important aspects of the SAM is its influence on the surface wind stress that affects the ocean circulation. A regression of the monthly SAM index with the zonal wind stress anomaly is shown in Fig. 9. The upper panel represents the zonally averaged zonal wind stress in the mean (solid line) and the two extreme phases of the 

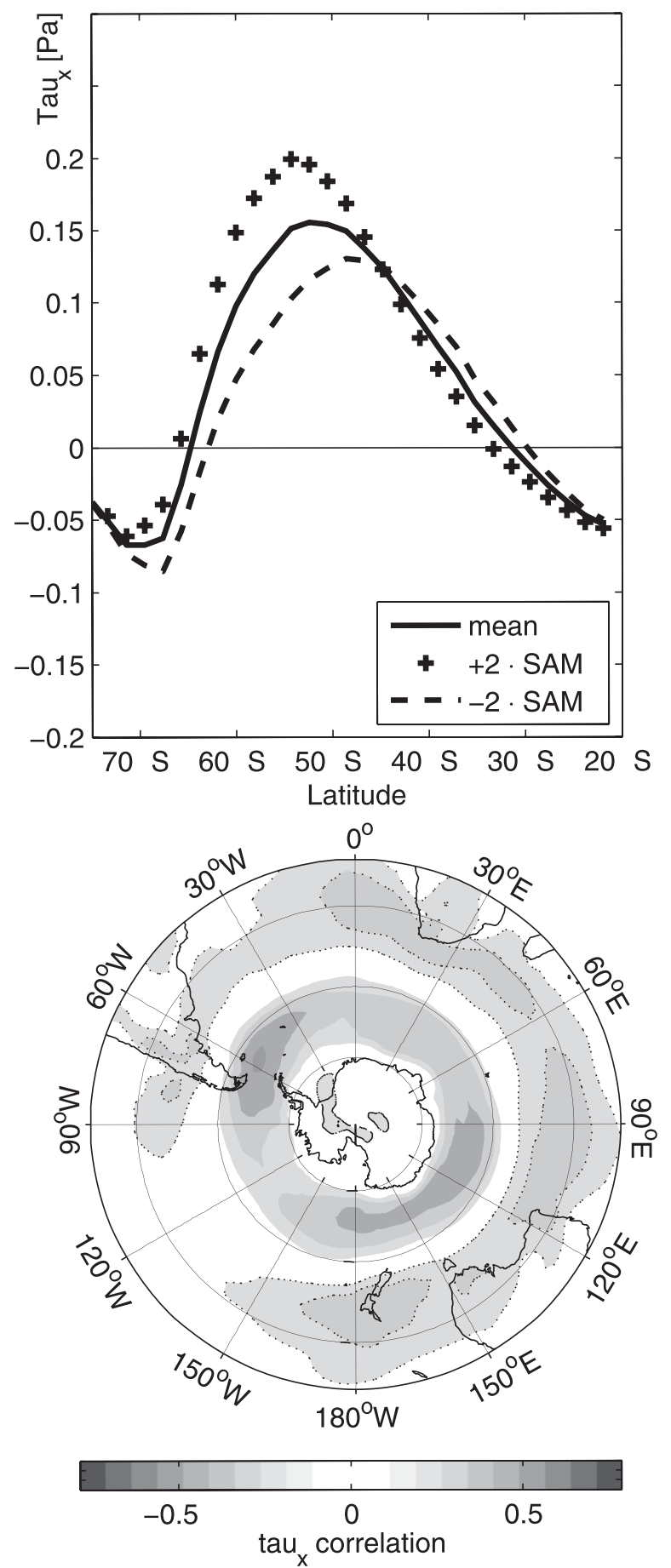

FIG. 9. (top) Zonally averaged zonal wind stress based on the post 1970 NCEP-NCAR reanalysis data. The pluses represent the zonally averaged zonal winds when the SAM index value is 2 . The dashed line represents zonally averaged zonal winds when the SAM index value is -2 . (bottom) Correlation of the monthly zonal wind stress with the SAM. Dashed contours denote westerly wind stress anomalies. A positive stress means that the atmosphere is accelerating the ocean in an eastward direction.
SAM. This represents roughly the change between the conditions during the 1970s and the more recent decade. While south of $45^{\circ} \mathrm{S}$ the wind stress increases during a positive trend of the SAM, the reverse is true equatorward. The lower panel shows the coherence of the monthly correlation between zonal wind stress and the SAM index. Aside from some weakly increased correlations in the Drake Passage and south of Australia a mostly zonally coherent signal is found between $50^{\circ}$ and $70^{\circ} \mathrm{S}$.

The only long surface pressure time series from the Antarctic region is located on the Antarctic Peninsula at $60^{\circ} \mathrm{S}$ (Orcadas). Unfortunately, its monthly correlation with the SAM is with 0.4 rather low (see Table 1). The lower correlation is also consistent with the findings of the reanalysis data (Fig. 2, shading), and thus this great record is only of limited value to constrain the SAM index prior to the advent of systematic atmospheric observation in the Antarctic region during the 1940-60 period.

The extended new SAM index enabled a fresh look the statistics of decadal trends in the SAM index. The strong upward trend of the SAM index in the recent decades is just slightly stronger than similar events in the past (Fig. 7). Only half of the month shows a remarkable trend over the last $35 \mathrm{yr}$ when compared to the long-term variance (Fig. 8). Thus, on the basis of the new SAM index trend analyses, one must not conclude that something unprecedented has happened with the SAM in the recent decades.

The new SAM index is publicly available (online at http://www.ifm-geomar.de/ SAM).

Acknowledgments. Phil Jones (Climate Research Unit) kindly provided the station pressure data. Discussions with Gareth Marshall (British Antarctic Survey), Julie Jones (University of Sheffield), Ryan Fogt (Bird Polar Research Center), Yochanan Kushnir (LamontDoherty Earth Observatory), and David Thompson (Colorado State University) improved the construction of the proxy SAM index. Felix Tubiana (Lamont-Doherty Earth Observatory) helped with several of the calculations. Helpful comments and suggestions provided by two reviewers improved the manuscript.

\section{REFERENCES}

Allan, R. J., and T. J. Ansell, 2006: A new globally complete monthly historical gridded mean sea level pressure data set (HadSLP2): 1850-2004. J. Climate, 19, 5816-5842.

Arblaster, J. M., and G. A. Meehl, 2006: Contributions of external forcings to southern annular mode trends. J. Climate, 19, 2896-2905. 
Butler, A. H., D. W. J. Thompson, and K. R. Gurney, 2007: Observed relationships between the Southern Annular Mode and atmospheric carbon dioxide. Global Biogeochem. Cycles, 21, GB4014, doi:10.1029/2006GB002796.

Cai, W., and T. Cowan, 2007: Trends in Southern Hemisphere circulation in IPCC AR4 models over 1950-99: Ozone depletion versus greenhouse forcing. J. Climate, 20, 681-693.

— , P. H. Whetton, and D. J. Karoly, 2003: The response of the Antarctic Oscillation to increasing and stabilized atmospheric $\mathrm{CO}_{2}$. J. Climate, 16, 1525-1538.

Fyfe, J. C., and O. A. Saenko, 2006: Simulated changes in the extratropical Southern Hemisphere winds and currents. Geophys. Res. Lett., 33, L06701, doi:10.1029/2005GL025332.

—, G. J. Boer, and G. M. Flato, 1999: The Arctic and Antarctic oscillations and their projected changes under global warming. Geophys. Res. Lett., 26, 1601-1604.

Gillett, N. P., and D. W. J. Thompson, 2003: Simulation of recent Southern Hemisphere climate change. Science, 302, 273-275.

— T. D. Kell, and P. D. Jones, 2006: Regional impacts of the Southern Annular Mode. Geophys. Res. Lett., 33, L23704, doi:10.1029/2006GL027721.

Gong, D., and S. Wang, 1999: Definition of Antarctic oscillation index. Geophys. Res. Lett., 26, 459-462.

Goodwin, I. D., T. D. van Ommen, M. A. J. Curran, and P. A. Mayewski, 2004: Mid latitude winter climate variability in the Southern Indian and south-west Pacific regions since 1300 AD. Climate Dyn., 22, 783-794, doi:10.1007/S00382-004-0403-3.

Gordon, A. J., M. Visbeck, and J. Comiso, 2007: A possible link between the Weddell polynya and the Southern Annular Mode. J. Climate, 20, 2558-2571.

Hall, A., and M. Visbeck, 2002: Synchronous variability in the Southern Hemisphere atmosphere, sea ice, and ocean resulting from the annular mode. J. Climate, 15, 3043-3057.

Hendon, H. H., D. W. J. Thompson, and M. C. Wheeler, 2007: Australian rainfall and surface temperature variations associated with the Southern Hemisphere annular mode. J. Climate, 20, 2452-2467.

Hines, K., D. Bromwich, and G. Marshall, 2000: Artificial surface pressure trends in the NCEP-NCAR reanalysis over the Southern Ocean and Antarctica. J. Climate, 13, 3940-3952.

Jones, J. M., and M. Widmann, 2003: Instrument and tree-ring estimates of the Antarctic Oscillation. J. Climate, 16, 3511-3524.

Jones, P. D., 1991: Southern Hemisphere sea-level pressure data: An analysis and reconstructions back to 1951 and 1911. Int. J. Climatol., 11, 585-607.

Kidson, J. W., 1999: Principal modes of Southern Hemisphere low-frequency variability obtained from NCEP-NCAR reanalyses. J. Climate, 12, 2808-2830.

Kushner, P. J., I. M. Held, and T. L. Delworth, 2001: Southern Hemisphere atmospheric circulation response to global warming. J. Climate, 14, 2238-2249.

Lefebvre, W., H. Goosse, R. Timmermann, and T. Fichefet, 2004: Influence of the Southern Annular Mode on the sea iceocean system. J. Geophys. Res., 109, C09006, doi:10.1029/ 2004JC002403.

Lenton, A., and R. J. Matear, 2007: Role of the Southern Annular
Mode (SAM) in Southern Ocean $\mathrm{CO}_{2}$ uptake. Glob. Biogeochem. Cycles, 21, GB2016, doi:10.1029/2006GB002714.

Lovenduski, N. S., and N. Gruber, 2005: The impact of the Southern Annular Mode on Southern Ocean circulation and biology. Geophys. Res. Lett., 32, L11603, doi:10.1029/ 2005 GL022727.

,-- S. C. Doney, and I. D. Lima, 2007: Enhanced $\mathrm{CO}_{2}$ outgassing in the Southern Ocean from a positive phase of the Southern Annular Mode. Global Biogeochem. Cycles, 21, GB2026, doi:10.1029/2006GB002900.

Marshall, G. J., 2003: Trends in the Southern Annular Mode from observations and reanalyses. J. Climate, 16, 4134-4143.

Meredith, M. P., and A. M. Hogg, 2006: Circumpolar response of Southern Ocean eddy activity to a change in the Southern Annular Mode. Geophys. Res. Lett., 33, L16608, doi:10.1029/ 2006 GL026499.

— , P. L. Woodworth, C. W. Hughes, and V. Stepanov, 2004: Changes in the ocean transport through Drake Passage during the 1980 s and 1990s, forced by changes in the Southern Annular Mode. Geophys. Res. Lett., 31, L21305, doi:10.1029/ 2004GL021169.

Mo, K. C., 2000: Relationships between low-frequency variability in the Southern Hemisphere and sea surface temperature anomalies. J. Climate, 13, 3599-3610.

Miller, R. L., G. A. Schmidt, and D. T. Shindell, 2006: Forced annular variations in the 20th century Intergovernmental Panel on Climate Change Fourth Assessment Report models. J. Geophys. Res., 111, D18101, doi:10.1029/2005JD006323.

Oke, P. R., and M. H. England, 2004: On the oceanic response to changes in the latitude of the Southern Hemisphere subpolar westerly winds. J. Climate, 17, 1040-1054.

Schneider, D. P., E. J. Steig, T. D. van Ommen, D. A. Dixon, P. A. Mayewski, J. M. Jones, and C. M. Bitz, 2006: Antarctic temperatures over the past two centuries from ice cores. Geophys. Res. Lett., 33, L16707, doi:10.129/2006GL027057.

Sen Gupta, A., and M. H. England, 2006: Coupled oceanatmosphere-ice response to variations in the Southern Annular Mode. J. Climate, 19, 4457-4486.

Sexton, D. M. H., 2001: The effect of stratospheric ozone depletion on the phase of the Antarctic Oscillation. Geophys. Res. Lett., 28, 3697-3700.

Silvestri, G. E., and C. S. Vera, 2003: Antarctic Oscillation signal on precipitation anomalies over southeastern South America. Geophys. Res. Lett., 30, 2115, doi:10.1029/2003GL018277.

Thompson, D. W. J., and J. M. Wallace, 2000: Annular modes in the extratropical circulation. Part I: Month-to-month variability. J. Climate, 13, 1000-1016.

_ Hemisphere climate change. Science, 296, 895-899.

_ J. M. Wallace, and G. C. Hegerl, 2000: Annular modes in the extratropical circulation. Part II: Trends. J. Climate, 13, 10181036.

Verdy, A., J. Marshall, and A. Czaja, 2006: Sea surface temperature variability along the path of the Antarctic Circumpolar Current. J. Phys. Oceanogr., 36, 1317-1331.

Visbeck, M., and A. Hall, 2004: Reply. J. Climate, 17, 2255-2258. 